\title{
Unusual combination of gestational trophoblastic neoplasias: case report
}

\section{Combinação rara de neoplasias trofoblásticas gestacionais: caso clínico}

Irina Dulce Tapadinhas Matos Ramilo; Gustavo Martins Mendinhos²; Fernando Antônio Ferreira da Igreja $a^{3}$; Maria Clara Morais Aleluia

Rosete Maria Amorim Novais Nogueira; Fernando Manuel Ribeiro Gomes ${ }^{6}$; José Manuel Silva Pereira ${ }^{7}$

\begin{abstract}
Gestational trophoblastic disease comprises a heterogeneous group of lesions arising from abnormal proliferation of trophoblastic cells. An elevation of human chorionic gonadotropin after evacuation of a molar pregnancy should suggest the hypothesis of a persistent gestational trophoblastic neoplasia. We present a rare case of coexistence of choriocarcinoma and placental-site trophoblastic tumor in the same tumor, whose diagnosis was made based on the correlation of morphological, microscopic and immunocytochemical studies, due to the difficulty in diagnosing these mixed tumors based on conventional histology only.
\end{abstract}

Key words: choriocarcinoma; gestational; trophoblast; neoplasm; chemotherapy.

\section{INTRODUCTION}

Gestational trophoblastic disease (GTD) comprises a heterogeneous group of placental lesions arising from abnormal proliferation of trophoblast. After evacuation of a complete hydatidiform mole (HM), the trophoblastic tissue may persist in $20 \%$ of the patients and progress to a gestational trophoblastic neoplasia (GTN). The invasive HM, the placental choriocarcinoma (CC) and the placental-site trophoblastic tumor (PSTT) are grouped under the heading GTNs and have a potential for early vascular invasion and metastasis ${ }^{(13)}$.

CC differs from any type of villous trophoblast and is the most aggressive GTN, occurring in approximately $1 / 20,000$ 40,000 pregnancies and in $1 / 40$ complete $\mathrm{HM}^{(11)}$. Histologically, it is a neoplasm with a typical biphasic pattern of cytotrophoblast or intermediate trophoblast, syncytiotrophoblast with cellular pleomorphism, and anaplasia in the absence of chorionic villi (except for the rare cases identified in mature placentas). The invasion of adjacent tissues is many times accompanied by extensive necrosis and hemorrhage, and angioinvasion may be present $^{(1,2,15)}$. This tumor presents with elevated levels of the beta subunit of human chorionic gonadotropin ( $\beta$-hCG) and is highly chemosensitive $^{(1,12)}$.

PSTT is the rarest GTN, and corresponds to less than $0.2 \%$ of all GTD cases. It may also develop after any type of pregnancy, mainly confined to the uterus, and in $70 \%$ of the cases displays benign behavior. However, there is no specific clinical or pathologic characteristic to predict its eventual malignancy. At histology, it presents as a monomorphic proliferation of extravillous or intermediate trophoblast cells (it belongs to the subgroup of intermediate trophoblastic tumors [ITTs]) with occasional giant multinucleated cells that infiltrate and split myometrium or endomyometrium ${ }^{(7)}$. Chorionic villi are seldom found, and the biphasic pattern typical of CC is absent. Normally, a variable amount of inflammation and necrosis is identified, but the marked necrosis and the hemorrhage typical of CC are not present. This tumor secretes small amounts of $\beta$-hCG; as a result,

First submission on $03 / 07 / 14$; last submission on 18/09/14; accepted for publication on 19/09/14; published on 20/10/14

1. Resident at the Gynecology Service of Hospital Prof. Doutor Fernando Fonseca, Amadora, Portugal.

2. Obstetrics and Gynecology specialist at Hospital Prof. Doutor Fernando Fonseca; consultant at the Gynecologic Oncology Unit of Hospital Prof. Doutor Fernando Fonseca.

3. Physician graduate of Universidade de São Paulo (USP); consultant at the Gynecologic Oncology Unit of Hospital Prof. Doutor Fernando Fonseca.

4. Director of Imaging Services at Hospital Prof. Doutor Fernando Fonseca.

5. Visiting assistant professor at Escola de Ciências da Saúde/Instituto de Ciências da Vida e da Saúde, Universidade do Minho, Braga, Portugal; director at the Anatomical

Pathology Laboratory of Centro de Genética Clínica, Porto, Portugal.

6. Consultant at the Medical Oncology Service of Hospital Prof. Doutor Fernando Fonseca.

7. Director of the Gynecology Service of Hospital Prof. Doutor Fernando Fonseca; lead consultant at the Gynecologic Oncology Unit of Hospital Prof. Doutor Fernando Fonseca. 
a large-volume tumor may be present before the increase of serum $\beta$-hCG levels ${ }^{(3)}$.

Histological characteristics, like deep myometrial invasion, high mitotic index (more than five mitoses per 10 high-power fields), tumor cells with clear cytoplasm and necrosis, are more common in more aggressive tumors ${ }^{(5)}$.

Immunohistochemistry shows a high proportion of cells positive for human placental lactogen (hPL) reflecting the origin of the lesion - the intermediate trophoblast -, and focal positivity for placental alkaline phosphatase (PLAP) and cytokeratins are markers of PSTT, with a specificity of around $60 \%{ }^{(14)}$. Positive immunohistochemical staining for inhibin $\alpha$ confirms the diagnosis of PSTT.

The role of adjuvant chemotherapy is controversial in PSTT, namely in stages I (Table), and there is no benefit in the 10-year survival rate. Therefore, unless risk factors for the disease recurrence are present, surgery is the most acceptable strategy ${ }^{(10)}$.

The coexistence of several GTNs in the same lesion is rare, and specific immunohistochemical studies are necessary to identify them. Genetic testing may complement diagnosis, since most PSTTs are diploid. In the GTN classification, the exclusion of mixed components by immunohistochemical studies that permit their identification is important, because their presence carries distinct clinical and therapeutical implications ${ }^{(6)}$. As chemotherapy has a limited role in the treatment of ITTs, it is especially problematic when they are mixed with CC.

In summary, staging and pre-therapeutic assessment of GTNs, especially of ITTs, are important to stratify patients and select the adequate treatment to each clinical case, normally based on the anatomical extension of the disease and the histological and immunohistochemical studies

\section{CASE REPORT}

A 30-year-old female primipara with fertility desire presents at the urgency service with a history of 10-week amenorrhea and genital hemorrhage. At admission she was afebrile, normotense and eupneic. She had slight uterine bleeding, uterus increased in size and painful to palpation, and adnexal areas with no alterations. From the laboratory point of view, only persistently high $\beta$-hCG levels (Figure 1) and subclinical hyperthyroidism stood out: hemoglobin - $11.5 \mathrm{~g} / \mathrm{dl}$; $\beta$-hCG - 2,531 mUI/ml; thyroid-stimulating hormone (TSH) $-0.01 \mathrm{mUI} / \mathrm{ml}$ (normal: 0.35-5.5); free thyroxine (T4) $-2.83 \mathrm{ng} / \mathrm{dl}$ (normal: $0.8-1.76$ ). The gynecologic ultrasound scan showed a heterogeneous mass filling the uterine cavity; trophoblastic disease was suspected, compatible with the hypothesis of complete HM. Chest radiograph did not reveal alterations. The patient underwent cervical dilation and aspiration of the uterine content. The histological diagnosis confirmed the pre-surgical hypothesis.

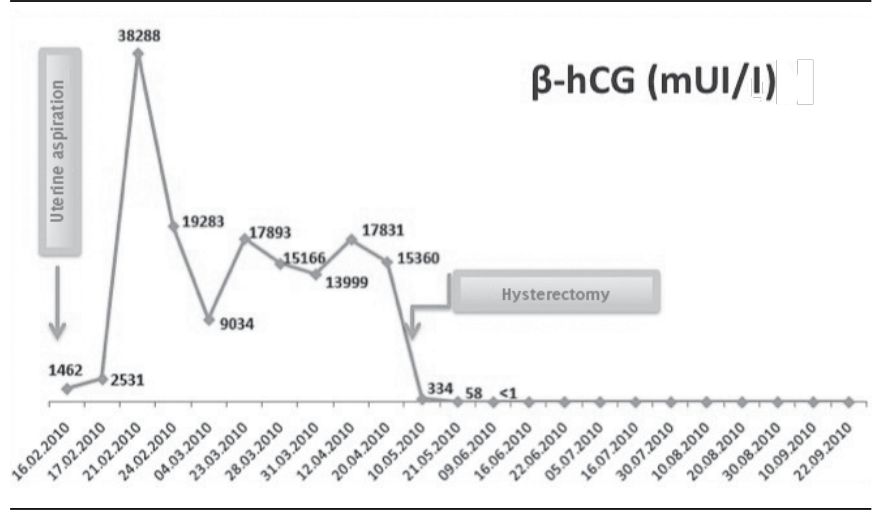

FIGURE 1 - Time evolution of serum $\beta$-bCG levels (Hospital Prof. Dr. Fernando Fonseca, Amadora, Portugal)

$\beta$-hCG: beta subunit of human chorionic gonadotropin.

During clinical follow-up, the patient kept the genital hemorrhage, and a considerable increase on $\beta$-hCG level was identified, reaching $38,288 \mathrm{mUI} / \mathrm{ml}$ in the fifth day after surgery (Figure 1). The pelvic ultrasound scan revealed ovaries increased in size due to the presence of anechogenic images suggestive of theca luthein cysts $(113 \times 87 \times 60 \mathrm{~mm})$; the uterus displayed a hypervascularized central area of heterogeneous structure, infiltrating the anterior and posterior myometrial wall

(Figure 2). A computed tomography (CT) scan was carried out in thoracic, abdominal and pelvic regions, evidencing globular uterus, with heterogeneous appearance, and central hypodense areas indicating residual lesion.

TABLE - Anatomical staging of GTN (FIG0)

\begin{tabular}{cc}
\hline Stage I & Disease confined to the uterus \\
Stage II & Disease extends outside the uterus, although limited to genital structures (adnexa, vagina and broad ligaments) \\
Stage III & Lung metastases, with or without known involvement of genital tract \\
Stage IV & All other metastatic sites \\
\hline
\end{tabular}

GTN: gestational trophoblastic neoplasia; FIGO: International Federation of Gynecology and Obstetrics. 
Due to the hypothesis of invasive mole/CC, and at the patient's request, after multidisciplinary discussion, total hysterectomy was performed, with conservation of anexa (Figure 2).

The histological examination showed cell component with extravillous trophoblast proliferation (immunohistochemical study positive for PLAP and inhibin [Figure 3]). Hemorrhage, coagulative necrosis, fibrinoid material at the area of ovum

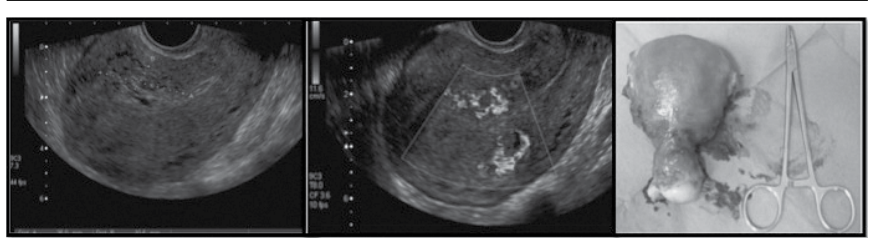

FIGURE 2 - Gynecologic ultrasound image and surgical specimen of the clinical case (Hospital Prof. Dr. Fernando Fonseca, Amadora, Portugal)

In the gynecologic ultrasound image, a hypervascularized central area of heterogeneous structure is visible, infiltrating the anterior and posterior wall of the uterine myometrium. Surgical specimen of hysterectomy with conservation of adnexa.

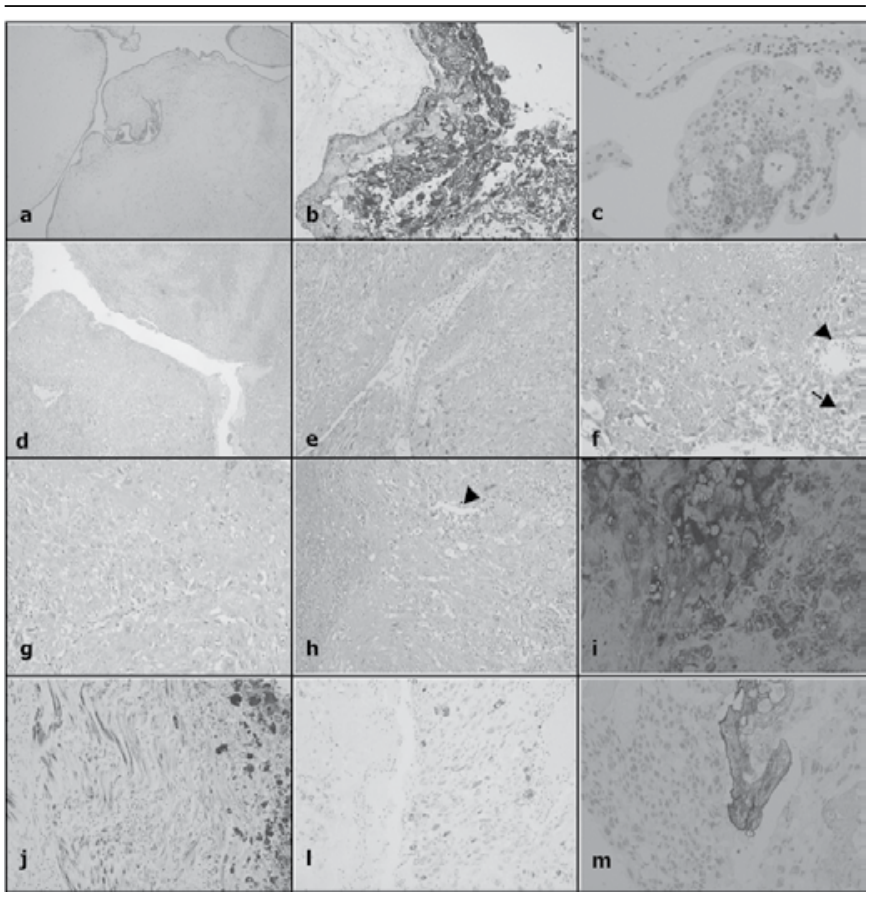

FIGURE 3 - Histological examination (Hospital Prof. Dr. Fernando Fonseca, Amadora, Portugal and Centro de Genética Clinica, Porto, Portugal)

Post-molar trophoblastic neoplasia: A) HE, villi with marked edema with formation of cistern with acellular center, without blood vessels, absence of normal villi; B) marked proliferation of trophoblast, positivity for $\beta-h C G(+++)$; C) PLAP (+).

Endomyometrial invasive lesion: D-H) HE, CC component with pleomorphism and acellular atypia, mitoses (arrow), polarization to vascular structures (arrow head), bemorrhage and necrosis.

Immunobistochemical profile: I) strongly marked $\beta-h C G(+++)$; I) strongly expressed AE1/ AE3 (+++), straight muscle fibers with weak expression for epithelial markers and in the PSTT component; L) weakly marked inbibin (+); M) moderately marked PLAP (++). HE: bematoxylin and eosin; $\beta-h C G$ : beta subunit of human chorionic gonadotropin; PLAP: placental alkaline phosphatase; CC: choriocarcinoma; PSTT: placental-site trophoblastic tumor: implantation, and inflammatory component favored the diagnosis of PSTT. Immunohistochemistry also revealed the proliferation component of villous trophoblast (positivity for $\beta$-hCG), thus confirming the coexistence of gestational CC (Figure 3).

At six months of clinical follow-up, $\beta$-hCG levels had returned to normal (43 days after intervention) and clinical picture, imaging and laboratory results were stable. Nowadays, three years after diagnosis, the patient is clinically well, in complete remission of the disease, without adjuvant therapy.

\section{DISCUSSION}

An invasive heterogeneous endomyometrial neoplasm was identified in this case, with hemorrhage and necrosis, which microscopically presents cellular pleomorphism and atypia, with low mitotic index. There is cell polarization to vascular structures, and the presence of hemorrhage and necrosis. Immunohistochemical studies show an expression common to PSTT and CC in a patient with a previous diagnosis of complete HM. The absence of a different "collision" pattern in both cellular components and their intimate coexistence in the same lesion make diagnosis many times difficult, requiring an immunohistochemical study to identify the different components, and thus, to reach a more precise classification regarding histogenesis of the several constituents (Figure 3). The presence of a histologically heterogeneous endomyometrial lesion, made of biphasic cellular proliferation areas, with cytotrophoblastic component or intermediate trophoblast and syncytiotrophoblast, (hCG +++ ), with no chorionic villi favors diagnosis of CC. Areas with mononuclear proliferation of extravillous or intermediate trophoblast (hPL++ PLAP++ and inhibin++), involving and infiltrating vessels with abundant coagulative necrosis, with fibrinoid material and inflammatory component (simulating the pattern of the normal area of ovum implantation) favor the diagnosis of PSTT.

Probably due to the dynamic and flexible differentiation capacity of tumoral trophoblast stem cells, mixed cases of ITT and other tumors have been found with morphology and immunohistochemistry characteristic of PSTT and CC inside the same tumor ${ }^{(4,6)}$.

Although rare forms of GTN, they can make histological classification difficult and their recognition is important because they need distinct therapies. Distinguishing ITT from CC is essential, given the limited value of chemotherapy in ITT, contrary to what happens with $\mathrm{CC}^{(9)}$.

Immunohistochemistry, by means of markers as human leukocyte antigen $\mathrm{G}$ (HLA-G), cluster of differentiation 10 (CD10), 
and hCG, is a good resource and may be useful in the differential diagnosis and identification of ITTs.

The factors of prognosis worsening present in this patient were, in histological terms, the deep myometrial invasion, and, in clinical terms, the high $\beta$-hCG levels, besides the coexistence of two GTNs and the fact that PSTT is not chemosensitive.

Thus, it is a rare combination of invasive endomyometrial lesion with morphological and immunohistochemical characteristics common to CC and PSTT. Molecular studies were not undertaken, and chromosomal anomalies are highly complex in CC with amplification of $7 \mathrm{p}$ and deletion of $8 \mathrm{p}$, without apparent relationship with the type of previous pregnancies; the diploid profile $\mathrm{XX}$ is present in most CCs. Malignant PSTTs show rare alterations in genome hybridization and in situ hybridization studies ${ }^{(8)}$.

A mixed trophoblastic tumor with CC and PSTT component is an extremely rare presentation, but highly curable and with good prognosis, if detected early( ${ }^{(6)}$. As the clinical spectrum and presentation of GTNs vary a lot, early diagnosis and the timely institution of therapy are fundamental to a favorable clinical outcome $^{(12)}$.

\section{RESUMO}

A doença trofoblástica gestacional compreende um grupo heterogêneo de lesões decorrentes da proliferação anormal de células trofoblásticas. A elevação da subunidade beta da gonadotrofina coriônica humana ( $\beta$ - $b C G)$ após a evacuação de uma gravidez molar levanta a hipótese diagnóstica de neoplasia trofoblástica gestacional persistente. Apresentamos um caso raro de coexistência de coriocarcinoma e tumor trofoblástico do leito placentário em um mesmo tumor, cujo diagnóstico foi efetuado com base na correlação dos estudos morfológicos, microscópicos e imuno-bistoquímicos, dada a dificuldade de diagnosticar esses tumores mistos com base apenas no exame bistológico convencional.

Unitermos: coriocarcinoma; gestacional; trofoblasto; neoplasia; quimioterapia.

\section{REFERENCES}

1. BERKOWITZ, R. S.; GOLDSTEIN, D. P. Gestational trophoblastic disease. In: BEREK, J. S. (Ed.). Berek \& Novak's Gynecology. 14. ed. Philadelphia: Lippincott Williams \& Wilkins, 2007. p. 1581-604.

2. CRUM, C. P. The female genital tract. In: COTRAN, R.; KUMAR, V.; COLLINS, T. (Eds.). Pathologic basis of disease. 6. ed. Philadelphia: WB Saunders Company, 1999. p. 1084-9.

3. DENNY, L. et al. Placental site trophoblastic tumor: three case reports and literature review. Gynecol Oncol, v. 59, n. 2, p. 300-3, 1995.

4. FUKUNAGA, M.; USHIGOME, S. Malignant trophoblastic tumors: immunohistochemical and flow cytometric comparison of choriocarcinoma and placental site trophoblastic tumors. Hum Pathol, v. 24, n. 10, p. 1098$106,1993$.

5. HORN, L. C. et al. Histopathology of gestational trophoblastic disease. An update. Pathologe, v. 30, n. 4, p. 313-23, 2009.

6. KALHOR, N. et al. Immunohistochemical studies of trophoblastic tumors. Am J Surg Pathol, v. 33, n. 4, p. 633-8, 2009.

7. LUK, W. Y.; FRIEDLANDER, M. A fibroid or cancer? A rare case of mixed choriocarcinoma and epithelioid trophoblastic tumour. Case Rep Obstet Gynecol, v. 2013, p. 1-2, 2013.
8. PEI, H. Gestational choriocarcinoma. In: HUI, P. (Ed.). Gestational trophoblastic disease: diagnostic and molecular genetic pathology. Humana Press, Springer Science \& Business Media, 2011. p. 127137.

9. RAMONDETTA, L. et al. Mixed choriocarcinoma in a postmenopausal patient. Int J Gynecol Pathol, v. 12, n. 3, p. 312-6, 2002.

10. SCHMID, P. et al. Prognostic markers and long-term outcome of placental-site trophoblastic tumours: a retrospective observational study. Lancet, v. 374, n. 9683, p. 48-55, 2009.

11. SEBIRE, N. J.; SECHL, M. J. Gestational trophoblastic disease: current management of hydatiform mole. BMJ, v. 337, p. 453-8, 2008.

12. SECKL, M. J. et al. Choriocarcinoma and partial hydatiform moles. Lancet, v. 356, n. 9223, p. 36-9, 2000.

13. SHIH, I. M. Gestational trophoblastic neoplasia - pathogenesis and potential therapeutic targets. Lancet Oncol, v. 8, n. 7, p. 642, 2007.

14. SHIH, I. M.; KURMAN, R.J. The pathology of intermediate trophoblastic tumors and tumor-like lesions. Int J Gynecol Pathol, v. 20, n. 1, p. 31-47, 2001.

15. STEVENS, A.; LOWE, J. Gynecological and obstetric pathology. In: CROWE, L. (Ed.). Pathology. 2. ed. Edimburgh: Mosby, 2000. p. 417-9.

\section{MAILING ADDRESS}

Irina Dulce Tapadinhas Matos Ramilo

Serviço de Ginecologia; Unidade de Ginecologia Oncológica do Hospital Prof. Doutor Fernando Fonseca; Amadora; Portugal; IC: 19, 2720-276; e-mail: irinaramilo@gmail.com. 